\title{
Organic farm conventionalisation and farmer practices in China, Brazil and Egypt
}

\author{
Myles Oelofse • Henning Hogh-Jensen • Lucimar S. Abreu • Gustavo F. Almeida • \\ Ahmed El-Araby • Qiao Yu Hui • Tursinbek Sultan • Andreas de Neergaard
}

Accepted: 12 May 2011 /Published online: 4 August 2011

(C) INRA and Springer Science+Business Media B.V. 2011

\begin{abstract}
Certified organic agriculture stipulates a range of principles and standards, which govern farmer practices. The recent global expansion of organic agriculture has raised new challenges for organic agriculture, particularly whether management practices in organic farms are subject to the forces of conventionalisation. We studied changes in agroecological practices in certified organic farms in China, Brazil and Egypt. The study takes departure in the conventionalisation hypothesis and the analysis is framed using organic and agroecological principles. The study focuses on agroecological design principles, inherent to organic agriculture, of diversity in crop production, pest, disease and weed management, and soil fertility management. The research design was as a multiple case study of five cases in China, Brazil and Egypt. We show that the adoption of organic agriculture has induced fundamental changes in organic farmer management practices, although agroecological practices of organic farmers do not fulfil
\end{abstract}

M. Oelofse $(\square) \cdot$ A. de Neergaard

Department of Agriculture and Ecology, Faculty of Life Sciences,

University of Copenhagen,

Thorvaldsensvej 40,

1871 Frederiksberg, Denmark

e-mail: myles@life.ku.dk

\section{H. Høgh-Jensen}

Department of Environmental Science,

Aarhus University,

Frederiksborgvej 399,

4000 Roskilde, Denmark

\section{S. Abreu}

Embrapa Environment,

P.O. Box 69, Jaguariúna, Sao Paolo, Brazil organic principles. The forces of conventionalisation exert a strong influence on changes in organic farmer practices. Organic 'niche' market crops with a high-value influence organic farmers' management decisions, particularly regarding the prioritisation of diversity in the cropping systems for agroecological purposes. The farming systems have therefore not undergone major changes of their cropping patterns. Furthermore, there was a general heavy reliance upon input substitution for pest and soil fertility management. This study thus presents new data and a novel analysis of the implications at the farm scale of the global expansion of organic agriculture, and the influence of conventionalisation on farmers practices.

Keywords Organic agriculture - Agroecology.

Conventionalisation $\cdot$ Sustainable agriculture $\cdot$ China .

Brazil · Egypt

\section{G. F. Almeida}

Center of Agrarian Sciences, Federal University of Sao Carlos, P.O. Box 13600-970, Araras SP-330, Brazil
A. El-Araby
Faculty of Agriculture, Ain Shams University, P.O. Box 68, 11241 Cairo, Egypt
Q. Y. Hui
College of Resource and Environmental Science,
China Agricultural University,
No. 2 Yuanmingyuan West Road,
Beijing, China
T. Sultan
Leibniz Institute of Agricultural Development in Central
and Eastern Europe (IAMO),
Theodor-Lieser-Strasse 2,
06120 Halle, Germany 


\section{Introduction}

Certified organic agriculture (OA) has grown rapidly in the past decades, emerging from a niche production system to a global-scale food sector. The global development of organic farming has been driven by a large demand for organic products in the global North (Raynolds 2004). Globally, approximately a quarter of all certified organic land was located in developing countries (Willer et al. 2009) and certified land areas in Africa, Asia and Latin America have grown substantially since 1999. Organic producers in developing countries constitute $82 \%$ of all organic producers worldwide (Willer and Kilcher 2010). The most important drivers of the development of organic agriculture in a development context are the new marketing and economic opportunities for certain commodities coupled with the promotion of $\mathrm{OA}$ as a strategy for rural development (Twarog 2006).

One of the primary objectives of organic agriculture is to increase the sustainability of agricultural systems (Rigby and Caceres 2001). Organic farming can be differentiated from other types of alternative agriculture in that organic practices are codified and regulated within a legal framework, which is ideologically founded in the organic principles, for example those developed by the International Federation of Organic Movements (IFOAM). The principles of organic agriculture are overarching guidelines for the development of organic agriculture and are articulated in an attempt to address the challenges of globalisation (Luttikholt 2007). Organic standards provide a tangible set of rules from which organic regulations can be derived and thus provide the rules which organic farmers should comply with.

Organic farming was originally conceived as an alternative to conventional agriculture practices. However, the rapid global growth of $\mathrm{OA}$ has raised a number of challenges for the future development of the organic movement (Byrne et al. 2006). A central concern is that the organic sector is moving on a trajectory towards what it started out as being a protest to (Rigby and Bown 2003). The trajectory toward more conventional agricultural practices in OA was termed the conventionalisation hypothesis by Buck et al. (1997), and has been rigorously debated by scholars since, a review of which is provided by Darnhofer et al. (2010). The conventionalisation hypothesis is based upon the notion that organic agriculture, due to rapidly increasing demand for high-value products is becoming 'industrialised' by becoming a modified version of modern conventional agriculture (Hall and Mogyorody 2001). Conventionalisation might include, for example, a move toward larger farms, capital intensification, labour being substituted by mechanisation, input substitution and increased dominance by agribusiness thus jeopardising the principles of organic agriculture and undermining the possible contribution of organic agriculture to sustainable development (Darnhofer et al. 2010; Hall and Mogyorody 2001). Focussing on the farm scale, Darnhofer et al. (2010) define conventionalisation as 'the introduction of farming practices that undermine the principles of organic farming'.

In light of the rapid global expansion of OA, a pertinent question is whether management practices on organic farms are subject to the forces of conventionalisation. Furthermore, it is relevant to consider how organic ideals, embodied in the principles, should be translated into farming practices, particularly on farms linked to global organic food chains and in regions far from the ideological cradle of OA. Under most circumstances, change is an essential process when farmers convert to OA. Conversion to OA typically requires structural changes to the farm rather than simple reduction or elimination of synthetic inputs from an otherwise conventional system (Lotter 2003). An agroecological approach, defined by Altieri (1995) as the design and management of agroecosystems applying ecological concepts, stresses system redesign as a principle. Altieri (1995) stresses four basic components of a sustainable agroecosystem: (1) the use of vegetative cover: cover crops and mulches, (2) regular supply of organic matter to promote soil biotic activity, (3) nutrient cycling mechanisms such as crop rotations, integrated farming, intercropping and legume use, and (4) pest regulation through biological control through biodiversity and natural enemies. The IFOAM standards pertaining to crop production at the farm scale focus upon diversity in crop production and ecosystem management; soil fertility management; and pest, disease, weed and growth management (IFOAM 2005).

Regulating organic farmer practices is not that problematic when banning certain inputs, however creating standards to promote certain activities, for example, which result in 'ecologically responsible' practices is a challenge (Rigby and Bown 2003). Darnhofer et al. (2010) advocate for an approach based upon the principles of organic agriculture using principle-based indicators of conventionalisation, which focus upon assessing on-farm changes following conversion.

The aim of this study was to test the conventionalisation hypothesis (Darnhofer et al. 2010; Hall and Mogyorody 2001) by assessing changes in agroecological practices on certified organic farms in China, Brazil and Egypt. The assessment took agroecological design principles, inherent to organic agriculture, into account by focussing upon diversity in crop production, pest, disease and weed management, as well as soil fertility changes. 


\section{Materials and methods}

\subsection{Data collection}

The research was designed as multiple case study of five different organic farming systems in China, Brazil and Egypt. We selected these three countries in order to cover a broad range of system types within different contexts. China and Brazil are amongst the top four developing countries with the largest area under organic agricultural management, whilst we selected Egypt as it has an established organic sector, which is an important supplier for the EU market. The primary parameters for selection of study sites were that the farmers should be (a) certified, (b) linked to an international or domestic organic market, (c) consist of clusters of roughly homogenous farmers, e.g. production system, and mode of organisation, and (d) consist of small-scale production sites as these have been of particular interest in the expansion of the North-South organic market chain.

We selected a random sample of organic farmers in each case area following the provision of farmer lists from certifiers, co-operatives and/or organic companies. As a reference of typical farmer conventional practices, we selected a sample of conventional farmers in close geographic proximity to the organic farmers with similar farm and production types. Details of the study sites and farm characteristics are presented in Table 1.

Following preliminary field observations and site selection, we conducted an extensive semi-structured survey over a number of farm visits. The survey acquired detailed production data as well as qualitative data of farmers' perceptions of aspects following conversion to OA.
Additional quantitative and qualitative data were collected during follow-up verification visits. Data was collected in 2007 and 2008 for all study sites.

\subsection{Analytical framework}

The analysis of farmers' agronomic practices in the sample takes departure in the IFOAM principles and basic standards (IFOAM 2005). Organic farmers' management practices within each study site are presented and analysed in four categories: diversity in crop production, pest and disease management, weed management and soil fertility management. The analysis assumes a dual approach. The first, which is descriptive, compares what the organic standards prescribe with farmers actual practices. Where applicable, these practices are compared with conventional farmers' practices, considered as a reference. For the second approach, we present proxy indicators for each of the four categories, inspired by the agroecological analytical approach set out by Bockstaller et al. (1997), although taking departure in practices prescribed by the organic standards and principles, as called for by Darnhofer et al. (2010). The criteria for evaluation of the four categories are presented below, including a brief discussion of the relevance for organic agriculture.

\subsubsection{Diversity in crop production}

The promotion, and maintenance, of agrobiodiversity is considered one of the key elements of organic agriculture (Parrott and Marsden 2002). The organic standards require that 'Diversity in crop production and activity shall be assured by minimum crop rotation requirements and/or

Table 1 Characteristics of the study sites and sample

\begin{tabular}{|c|c|c|c|c|c|}
\hline $\begin{array}{l}\text { Case name } \\
\text { Location }\end{array}$ & $\begin{array}{l}\text { Jilin } \\
\text { Jilin, China }\end{array}$ & $\begin{array}{l}\text { Shandong } \\
\text { Shandong, China }\end{array}$ & $\begin{array}{l}\text { Itapolis } \\
\text { Sao Paulo, Brazil }\end{array}$ & $\begin{array}{l}\text { Ibiuna } \\
\text { Sao Paulo, Brazil }\end{array}$ & $\begin{array}{l}\text { Fayoum } \\
\text { Fayoum, Egypt }\end{array}$ \\
\hline Production system & Soy-maize & Vegetable-grain & Fruit & Vegetable & Herb-vegetable-grain \\
\hline No. of farms & $\mathrm{O}: 20 \mathrm{C}: 15$ & O:21 C:6 & O:9 C: 8 & O: $33 \mathrm{C}: 6$ & $\mathrm{O}: 17 \mathrm{C}: 5$ \\
\hline \multirow[t]{2}{*}{ Farm size (ha) } & O: $15.8(6.7)$ & O: $0.40(0.19)$ & O: $29.3(17.7)$ & O: $3.3(2.8)$ & O: $13.1(10.6)$ \\
\hline & C: $5.8(2.5)$ & C: $0.34(0.07)$ & C: 31.0 (21.9) & C:3.9 (2.6) & C: $2.8(3.2)$ \\
\hline \multirow[t]{2}{*}{ Livestock units (LU/ha) } & O: $0.6(0.4)$ & O: $0.4(0.6)$ & O: $0.105(0.10)$ & O: $0.03(0.01)$ & O: $2.0(1.7)$ \\
\hline & C: $0.1(0.1)$ & C: $1.8(2.8)$ & C: $0.43(0.9)$ & C: 0.8 (1.59) & C: 2.4 (1.9) \\
\hline Mean years organic & $5.2(2.0)$ & $12.0(0.4)$ & $6.2(1.9)$ & $8.6(2.8)$ & $8.9(3.7)$ \\
\hline Latitude & $\mathrm{N} 43^{\circ} 37^{\prime \prime}-43^{\circ} 47^{\prime \prime}$ & N $35^{\circ} 59^{\prime \prime}-36^{\circ} 06^{\prime \prime}$ & S $21^{\circ} 22^{\prime \prime}-21^{\circ} 38^{\prime \prime}$ & S $23^{\circ} 42^{\prime \prime}-23^{\circ} 48^{\prime \prime}$ & N $29^{\circ} 10^{\prime \prime}-29^{\circ} 31^{\prime \prime}$ \\
\hline Longitude & E $128^{\circ} 24^{\prime \prime}-128^{\circ} 46^{\prime \prime}$ & E $116^{\circ} 50^{\prime \prime}-116^{\circ} 54^{\prime \prime}$ & $\mathrm{W} 48^{\circ} 36^{\prime \prime}-48^{\circ} 59^{\prime \prime}$ & $\mathrm{W} 47^{\circ} 03^{\prime \prime}-47^{\circ} 10^{\prime \prime}$ & E $30^{\circ} 31^{\prime \prime}-31^{\circ} 02^{\prime \prime}$ \\
\hline Altitude (m asl) & $370-410$ & $80-90$ & $480-530$ & $840-1,214$ & $-40-40$ \\
\hline Precipitation $\left(\mathrm{mm} \mathrm{year}^{-1}\right)$ & 600 & $500-650$ & 1,300 & $1,500-2,000$ & 10 \\
\hline Mean annual temp $\left({ }^{\circ} \mathrm{C}\right)$ & 2.4 & 14 & 24 & 22 & 24 \\
\hline
\end{tabular}

Mean values are presented followed by the standard deviation in parenthesis ( $O$ organic, $C$ conventional)

$L U$ livestock units, definition: $1 \mathrm{LU}=0.5-0.7$ cattle $=4$ pigs $=100$ chickens/broilers $=1.25$ horses $($ FAO 2003) 
variety of plantings', recommending that 'a wide range of crops and varieties should be grown to enhance the sustainability, self-reliance and biodiversity value of organic farms'. Diversity in crop production is assessed, firstly, by presenting and discussing organic farmers' crop rotation practices and what changes there have been since conversion. Secondly, by calculating a crop diversity index and thirdly, by considering the portion of the farm set aside for ecosystem management. Crop diversity is assessed by calculating a Crop Diversity Index (CDI). The CDI is created using the Shannon Index $(\mathrm{H})$, which is an index that reflects both species evenness as well as abundance (Armsworth et al. 2004). The Shannon Index is defined as follows:

$H=-\sum_{i=1}^{j} p_{i} \ln p_{i}$

where, $J$ is the number of cultivated crops, $p_{i}$ denotes the proportion of the farm area belonging to the $i$ th crop species, and $\ln$ is the natural logarithm. Thus, for a farm with a monoculture, $p_{i}$ will equal to one, resulting in a diversity value of 0 . An increasing in the number of species (abundance) combined with increasing species evenness will result in a higher value for $\mathrm{H}$. The crop diversity index is aggregated for organic farms in each case study and compared to that of the conventional sample. The CDI covers 1 year in Jilin (one cropping season annually) and Itapolis (perennial system). For Shandong, the index is calculated for both spring and autumn cropping seasons whilst for Fayoum, which has two main growing seasons annually, the index is calculated for one growing season. A diversity index was not calculated for Ibiuna since organic farmers grow a broad range of different crops on very small plots with various phases of growth and crop types.

\subsubsection{Pest, disease and weed management}

The general principles in the IFOAM basic standards state that the management of pests diseases and weeds should occur through the application of biological and cultural means. Cropping practices (rotations, intercropping and diversity) and soil fertility practices are central to the management of pests, diseases and weeds (Altieri 1999). The organic standards permit the use of inputs should preventative measures not be sufficient, and the standards recommend a range of practices for pest, disease and weed control including appropriate choice of crop species and variety, rotations and mechanical controls. Pest, disease and weed management in the case studies are assessed using a four-phase model as presented by Zehnder et al. (2007). Each phase in the model represents a move from preventative measures to control measures. The first phase consists of preventative measures (crop rotations, soil management and site selection), the second phase is vegetation management to enhance natural enemies, whilst the third consists of biological control. The fourth phase consists of the use of approved pesticides. Similarly, for weed control, the four steps prioritise preventative measures that either reduce weed emergence (using crop sequencing and crop choice, cover crops and tillage) or reduce weed competition using cultural methods such as crop type selection, planting pattern and fertilisation strategy (Barberi 2002). Besides preventative measures, organic farmers may also use direct weed control using mechanical methods such as inter-row weeding using specifically designed implements and harrowing.

\subsubsection{Soil fertility management}

Soil management is considered the foundation of organic production and should be based upon nutrient cycling through the return of microbial plant or animal material to increase or maintain soil fertility (IFOAM 2005). Organic farms rely on the management of soil organic matter in order to enhance chemical, biological and physical properties of the soil (Watson et al. 2002). Nutrient cycling through materials of microbial, plant or animal origins (composts) should form the core of soil fertility management, although the organic standards allow limited use of mineral fertilisers in certain cases. (IFOAM 2005). Organic farmers' soil fertility management practices are assessed based upon a presentation and discussion of current practices and input types and amounts and how practices align with the requirements of the organic standards.

\subsubsection{Towards principle-based indicators}

In their review of conventionalisation of organic agriculture, Darnhofer et al. (2010) discuss whether, and how, a set of principle-based indicators of conventionalisation can be developed for organic agriculture. Since organic agriculture is value-based, the assessment of how 'organic' practices are can become rather subjective. Here, we set forward a set of indicators which attempt to overcome this. To round off our analysis, and based on the analysis of the four central areas, we provide an overall assessment of organic farmers' agroecological practices. Inspired by Guthman (2000), we use a scoring system for each aspect analysed, based on the following criteria, where farmers receive a point for each criteria fulfilled:

Diversity The farmer has a stated crop rotation; inclusion of fertility building crops in rotation; crop diversity: where values of $0-0.5,0.5-1$, and $>1$ score $0,0.5$ and 1 point, respectively. 
Soil fertility Use of organic inputs from plant or animal origin in fertility management; sourcing of organic inputs from on farm; non-use of naturally occurring mineral fertilisers.

Pest and disease management Vegetation management to enhance natural enemies; biological control used for management of pests and disease; non-use of permitted applied control measures on farm.

Weed management Active planning and use of innovative weed control measures, for example mulching.

The criteria are developed based upon recommended practices and principles, and not fulfillment of the basic standards required for conversion. We scored each farmer within each case study, where a maximum score of 10 can be attained ( 9 for Ibiuna since there was no crop diversity score here). Results are presented as aggregated scores for each case study, and, for the sake of comparison, we present scores from conventional farms.

\section{Results and discussion}

General characteristics of the farms studied in the respective case studies are presented in Table 1. A more detailed description of general characteristics of farms in each case study is set forward in Oelofse et al. (2010a).

\subsection{Diversity in crop production}

In Jilin, soybean is the primary cash crop for organic farmers. The rotation on organic farms consists of 3 years soybean followed by 1 year of maize. Organic farmers state that they grow soybean on the same land until the productivity starts to decline. Organic farmers' crop rotations are similar to typical conventional practices in the area, as reflected in the aggregated CDI (Table 2), which is similar for both farm types. With regard to crop choice and rotational practice, organic farmers in Jilin have made few changes to their management strategy. There is no land set aside for ecosystem management on organic farms in Jilin.

In Shandong, the organic system consists of various vegetable types, including spring and autumn cauliflower with an intercrop (relayed) of green beans, whilst some farmers had plots of asparagus. The organic company depicts crop choice, and thus crop rotations change from year-to-year. The crop diversity index (Table 2) reflects the similarities in the organic and conventional systems, the primary difference in the spring crop being the green bean intercrop. As with Jilin, there is no land set aside directly for ecosystem management.
Table 2 Mean crop diversity indices for organic and conventional farms

\begin{tabular}{lll}
\hline & Organic & Conventional \\
\hline Jilin & $0.42(0.32)$ & $0.34(0.17)$ \\
Shandong, Spring & $1.08(0.48)$ & $0.33(0.02)$ \\
Shandong, Autumn & $0.71(0.28)$ & $0.60(0.10)$ \\
Itapolis & $0.88(0.2)$ & $0.21(0.6)$ \\
Fayoum & $1.3(0.33)$ & $1.1(0.15)$ \\
\hline
\end{tabular}

Standard deviation is in parenthesis

The fruit systems in Itapolis are perennial, thus changes in cropping patterns cover a longer temporal scale than 1 year. The cooperative promotes crop diversification based primarily upon the reduction of economic risk, although there are also clear motives for increasing system ecological resilience. The CDI for Itapolis (Table 2) captures this move towards crop diversification as compared to the conventional sample, which has a larger degree of orange crops in monoculture. At the time of conversion to organic farming, the majority of organic farms relied primarily on orange grown in monoculture. The cooperative that assists organic farmers has advised and assisted farmers in the diversification of their production to include other fruits such as mango and guava. The organic sample in Itapolis contained examples of farmers experimenting with agroecological design principles, such as green manuring and intercropping of legumes (e.g. Crotalaria and Mucuna) and other crops (e.g. maize and cassava) in between the rows of fruit trees when planting new plots. Brazilian Environmental Regulation (Law 4771/65) stipulates that for Sao Paulo $20 \%$ of the farm should be set aside for ecosystem management. The mean proportion of land set aside on organic farms was $12 \%$ (ranging from $0 \%$ to $30 \%$ ). The organic certification body in Itapolis requires that farmers pursue a reforestation of set-aside land, giving the farmers a limited period in which to achieve this.

Organic farmers in Ibiuna, producing primarily leafy vegetables, stressed the importance of not growing the same crop type consecutively; however, few had a strictly applied crop rotation as the market demands specific high-value crops such as various varieties of lettuce. On average, approximately $29 \%$ of farmland was set aside in Ibiuna. This is most likely because the clearing of land in the forest area is prohibited as the area is an important water catchment area supplying Sao Paolo city. The organic cropping systems in Egypt closely resemble traditional, market-oriented cropping systems. There is a high degree of crop diversity (on both farm types, Table 2), reflected also in the crop rotations. One major difference between organic and conventional systems is crop choice. Typically, buyers of herbs and spices require that the crops be grown without 
the application of pesticides. Therefore, not many typical conventional farms grow these crops. The crop rotation on organic farms consists of a number of compartments. A typical rotation might be a wheat-clover-maize-clover rotation on one part of the farm, with herbs and spices (often perennial), such as coriander or chamomile are grown alternately on other plots, whilst a few farms also have some vegetables. The majority of organic farmers report that they have not altered their crop choice since conversion. Some have stopped growing corn as it cannot be sold organically, whilst others reported that tomato is too difficult to produce organically.

Of all five cases, only the perennial fruit system in Itapolis has undergone major changes to the design of the cropping system. In Jilin, Shandong and Ibiuna, the cropping pattern and sequence closely resembles conventional systems. This is not necessarily problematic as it most likely reflects what systems fit best in the local context. However, minor changes to the cropping sequence, such as incorporating legumes into the crop rotation are not evident in most cases presented - only if the legume has a market value, as is the case of green beans or soybeans. Finding an optimal balance between fertility building crops and economics is a general challenge for organic farmers (Schmutz et al. 2007); this is certainly reflected in the current examples.

Bakewell-Stone et al. (2008) expressed concern about the international market focus on specific high-value crops on organic farms in Tanzania. In our study, contracting companies play a central role in the selection and certification of certain farm and farmer typologies. Contracting companies typically base their selection on a number of criteria, as elaborated in Oelofse et al. (2010b). Important criteria include land access, biophysical conditions and the potential of farms to supply specific, marketable, organic crops. Therefore, farms only become certified organic when a certain target crop is present - this is the reason for the general lack of drastic change on the organic farms in this study. What often influenced crop choice in the five case study areas is thus heavily influenced by organic market demand, thus causing farmers to focus more on target crops than a holistic vision of their farm. The focus on target crops is perhaps best typified in Shandong, where farmers' production systems are split into organic-conventional compartments. The organic compartment only focuses upon the organic market crops (vegetables), with crop-choice strongly influenced by the contractors, whilst the conventional compartment consists of grains for local market and subsistence. The strong focus upon market crops is also exemplified in the soybean case in Jilin.

Does the prominent role of agribusiness, witnessed in our study, lead to a conventionalisation of farmers' practices? Certainly, agribusiness' involvement strongly influences farmers' cropping practices, which generally fall short of the organic principles, and resemble practices that are more conventional. Fraser (2006) recognises the possible threat of the international trade focus resulting in ecologically fragile monocultures. Certification and other transaction costs are high for organic farms and organic companies assisting or contracting farmers thus seek to reduce costs. However, Guthman (2004), in discussing the recent growth of OA succinctly states that 'It is inevitable therefore that organics will be influenced by the commercialism that is driving growth in the first place' and further posits that the involvement of agribusiness in OA will alter conditions for farmers through the logic of intensification. It is important to recognise that all farmers' operate within economic limitations; however, organic farmers' economic reliance upon contract crops will ultimately undercut farmers' 'ability to practice a deep form of organic farming' (Guthman 2004).

\subsection{Pest and disease management}

Crop protectants used for pest and disease control are listed in Table 3. Organic farmers in Jilin managed pests based on a 'wait-and-see' strategy and did not consider pests and disease a major problem. Some farmers use organically permitted protectants in the case of acute disease attacks. In Shandong, organic farmers use light lamps and insect traps to control pests, whilst some farmers spray with extracts of chilli and garlic as a preventative measure. In Itapolis, organic farmers considered pest and disease attacks their biggest production challenge. To control diseases, organic farmers typically spray with mixes containing various sulphur compounds mixed with mineral oils. Spraying for pest and disease control in fruit trees is typically done six times per year in conjunction with the application of foliar fertilisers. Most organic farmers felt that the efficacy of their sprays against vectors of plant diseases and pests was insufficient, exemplified by a number of organic farmers returning to conventional spraying practices to avoid further losses. Farmers returning to conventional practices were the farmers that converted to organic agriculture with the main purpose of achieving higher profits. They were not applying concepts of farm diversification and agroecological practices and at the first sign of yield reduction and lower income, they returned to conventional practices. However, some organic farmers also made efforts to plant beneficial plants to provide habitat for beneficial insects and recycle nutrients.

Organic farmers in Ibiuna pest and disease management strategy is based upon the use of a variety of control types, including natural sprays (chilli and garlic extracts), copper sulphate and various sulphur mixes, Bacillus thuringiensis 
Table 3 List of crop protectants used by organic farmers in one or more of the five case areas

\begin{tabular}{|c|c|c|c|c|c|c|}
\hline Type & Types used & Jilin & Shandong & Itapolis & Ibiuna & Fayoum \\
\hline Plant origin & Neem, chilli and garlic extracts, rotenone & & + & + & + & \\
\hline Mineral origin & $\begin{array}{l}\text { Sulphur, lime sulphur, copper sulphate, copper hydroxide, } \\
\text { mineral oils, silica dioxide }\end{array}$ & + & & + & + & + \\
\hline Microorganisms & Bacillus thuringiensis, Beauveria bassiana, Thrichogramma & & & & + & + \\
\hline Mechanical control & Mechanical and pheromone traps & & + & + & & + \\
\hline Other & Soap & & + & & + & \\
\hline
\end{tabular}

and Beauveria bassiana products and rotenone, which is a nonsynthetic pesticide, extracted from certain leguminous shrubs. In Fayoum, B. thuringiensis was the most widely used input by organic farmers, whilst many farmers also sprayed with sulphur mixes as well as copper sulphate to control diseases. Other control measures included Thrichogramma and pheromone traps.

The lack of system redesign on most organic farms, as discussed in the diversity section, is also evident in the curative nature of pest controls applied. However, prophylactic control measures might well be implicit to some of the farming systems studied here based upon farm history as well as farmers specific knowledge. For example, in Jilin and Fayoum, organic farmers' crop selection and rotations resemble traditional farming systems, which have been adapted to the area, thus organic farms might have implicitly adopted preventative strategies. Conventionalisation forces have influenced the lack of system redesign, which will influence farmers' pest and disease management strategies. Due to economic pressure, organic farmers contracted to certain crops are more inclined to rely upon input substitution, rather than system redesign (Guthman 2004). However, it is important not to underestimate the challenge organic farmers' face in managing pests and diseases in our case studies, particularly in tropical conditions. In all our cases, there are only a limited number of organic farms in the regions, thus organic farms are like small islands in a sea of conventionally managed land. Managing pests and diseases is a major challenge for organic farmers, particularly where knowledge access is limited. In Itapolis, pest and disease pressure is decisive for whether farmers can operate organically. Therefore, whether subject to conventionalisation or not, organic farmers in the contexts studied here require, firstly, substantial knowledge support during conversion and, secondly, a pragmatic set of rules and ideals governing organic farming which can allow the local context to be accounted for.

\subsection{Weed management}

The majority of organic farmers in Jilin control weeds by manual weeding two to three times per season. Farmers with access to tractors control weeds mechanically by harrowing. Organic farmers were aware of cultural methods to reduce weed pressure such as timing of planting, although planting time is dictated by the first rains given the very short frost-free period they have in the area. In Shandong, organic farmers control weeds manually, whilst black plastic is also used to control weeds. In Itapolis, organic farmers allow weedy grasses to grow between the rows. The grass is mowed three times a year and mulched under the trees. Weeding is done manually in Ibiuna, whilst organic farmers are aware of the benefits of rotations to decrease weed pressure. Plastic cover is used for weed control as well as moisture retention. In Fayoum, weeding is done manually, although some farmers harrow.

Organic farmers in the five cases primarily make use of labour demanding manual weed control (except for Itapolis). The use of black plastic, in Shandong and Ibiuna, is a source of controversy in organic farming (Guthman 2000); however, farmers may have few options when labour is expensive or unavailable.

An indicator of conventionalisation set forward is the substitution of labour by mechanisation (Hall and Mogyorody 2001). Manual weed control practices are reliant upon the supply of affordable labour. Faced by increasing labour costs and decreased labour supply, organic farmers require innovative technology for weed control, often involving increased mechanisation. Although increased mechanisation might not fully align with organic principles, which would demand a holistic preventative approach, the move from labour to mechanisation is a step in the agricultural intensification process.

\subsection{Soil fertility management}

Conversion to OA in all cases resulted in major amendments to farmers' soil fertility management strategies. The main change in practices was the cessation of use of mineral fertilisers leading to an increased use of organic fertiliser inputs of different types and origin. Table 4 provides an overview of farmers' organic input types and amounts. In Jilin, a large proportion of organic farmers' crop rotation consists of soybean, which is a legume and thus fixes nitrogen. Organic farmers' nutrient management 
strategies in Jilin build primarily upon this coupled with inputs of compost consisting of soy and maize residues, animal manure mixed with nutrient-rich forest soil in the ratio 6:2:2. Conventional farmers in Jilin use urea and diammonium phosphate and do not use compost.

Organic farmers in Shandong make use of off-farm and on-farm composted manure. The bulk of off-farm compost comes from a compost plant established by the organic company in conjunction with a pig farm. The pigs are fed residues from organic vegetable processing and compost is developed to supply organic farms contracted by the company. Farmers who own livestock apply composted manure to their crops. Organic farmers apply compound fertilisers to maize and wheat as on conventional farms.

In Itapolis, organic farmers require large amounts of animal manure and composts. Since the majority of organic farmers do not own animals, livestock and poultry manure are typically imported from neighbouring conventional farms and are often composted on the farm for 30 days prior to application. In addition to this, organic farmers apply a broad variety of foliar sprays, typically containing micronutrients. Conventional farmers

Table 4 Organic input types and aggregated amounts for each case area and farm type

\begin{tabular}{lcl}
\hline & Organic & Conventional \\
\hline Jilin & & \\
Mixed compost & $6,323(799)$ & 0 \\
Shandong & & \\
Composted pig manure & $3,668(715)$ & 0 \\
On-farm pig manure & $9,092(3,890)$ & $3,750(3,287)$ \\
Total Shandong & $12,760(4,520)$ & $3,750(3,287)$ \\
Itapolis & & \\
Composted chicken manure & $1,213(995)$ & $197(-)$ \\
Composted cattle manure & $2,149(3,584)$ & 0 \\
Mixed urban compost & $512(-)$ & 0 \\
Total Itapolis & $3,881(2,517)$ & $197(-)$ \\
Ibiuna & & \\
Composted chicken manure & $4,302(1,608)$ & $86(-)$ \\
Mixed compost & $1,436(1,033)$ & 0 \\
Composted cattle manure & $179(345)$ & 0 \\
Castor pomace & $1,562(1,549)$ & 0 \\
Bone meal & $173(145)$ & 0 \\
Total Ibiuna & $7,653(2,194)$ & $86(-)$ \\
Fayoum & & $27,192(7,027)$ \\
Cattle and chicken manure & $25,956(5,356)$ & \\
\hline & &
\end{tabular}

Amounts in kilogram per hectare, fresh weight, 95\% confidence interval in parenthesis

${ }^{\text {a }}$ Data for inputs in Fayoum not differentiated by types in Itapolis apply mineral fertilisers as well as lime for soil $\mathrm{pH}$ amendment.

In Ibiuna, organic farmers apply a broad range of organic inputs, as evident in Table 4 with the most important nutrient input being from composted poultry manure. Other input types include castor bean pomace, blood and bone meal and a variety of biofertilizer mixes applied as foliar sprays containing efficient microorganisms, manure, rice bran and a range of micronutrients. Conventional farmers in Ibiuna apply compound fertilisers, although a few farmers applied composted chicken manure.

Soil fertility management practices on organic and conventional farms in Fayoum were similar. The cropping systems investigated were integrated crop-livestock systems, and an important component is therefore the production of quality fodder by growing Egyptian clover (Trifolium alexandrium), which provides a substantial amount of nitrogen through fixation. A combination of composted livestock and poultry manures produced either on-farm or purchased from neighbouring farms as well as rock phosphate were the main inputs on organic farms. Some organic farmers used orthoclase, a mineral form of potassium. Organic inputs were central to conventional farmers' nutrient management strategy, although farmers also made use of various types of synthetic fertilisers, including super phosphates, urea, ammonium nitrate and potassium sulphate.

Organic farmers in the various case studies, in general, fulfil criteria stipulated by the organic standards. However, there is an evident large reliance upon nutrients acquired from off-farm sources through input substitution (see Oelofse et al. (2010a) for a detailed discussion). Whether this is necessarily problematic is an issue for discussion in organic agriculture, although reliance upon input substitution is a sign of conventionalisation. Lampkin (1990) stresses that the principle of closed nutrient cycles need not necessarily apply at the farm scale, an effective recycling of nutrients at the regional scale will be essential seen in the long term. Regional nutrient recycling is thus an important collaboration for organic farmers. However, the source of composts and manures is from conventional farms. In this regard, the recycling of nutrients of a mineral form is considered more problematic; for example, Kirchmann et al. (2008) question the sustainability of the reliance of organic farms upon nutrient transfer from conventional farms.

The reliance upon nutrients of synthetic origin does not align with the organic principles and is a clear sign of conventionalisation. The majority of organic farmers in our study practice input substitution with a strong reliance on 'conventional' nutrients. More control on organic farms would most likely lead to organic farmers reverting to 
conventional practices, as farms relying on imported inputs simply would not be able to operate without them.

\subsection{Aggregated assessment}

The results of the overall assessment are presented in Fig. 1. Scores on organic farms range from approximately four to six, lowest in Jilin and highest in Itapolis for organic farms. Scoring for organic and conventional farms was similar in Fayoum, whilst organic farms scored substantially higher than conventional farms in all other cases.

The scores reflect our findings in the previous sections, as expected. Presented as a comparison of organic and conventional practices, the aggregated scores show that, firstly, the adoption of organic practices does lead to a change in farmers' practices. Secondly, an aggregated analysis of this nature might 'mask' the effects of conventionalisation - it is not possible to conclude that the forces of conventionalisation are a strong driver of the differences in farmers' practices. The value of this type of aggregated analysis can be discussed, this is one way of doing things. However, an operational system of this nature for certification purposes would be extremely data demanding and raise an important question of which direction organic agriculture in a global perspective would like to move.

\section{Conclusion}

Darnhofer et al. (2010) stress the need for us to assess whether changes in practices on organic farms comply with the values and principles inherent to OA. The results

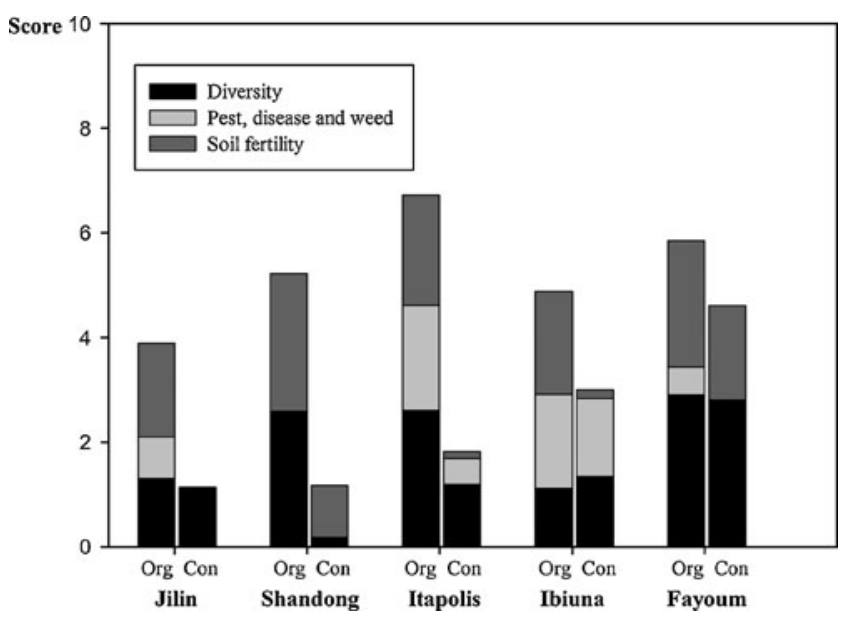

Fig. 1 Scores from the agroecological analysis for organic and conventional farmers in five case areas; Org organic farmers, Con conventional farmers presented in this research provide new knowledge of what types of changes in farming practices participation in global organic food chains might incur. Our findings show that organic farming does have a transformative potential, although the driver of this transformation is inextricably linked to the powers of the agro-industrial food chain. Although the adoption of organic agriculture has induced a number of fundamental changes to farmers' management practices, the evidence presented here suggests that farming practices do not wholly fulfil agroecological principles, and that the forces of conventionalisation exert a strong influence on farmers' practices. Organic 'niche' market crops with a high-value influence organic farmers' management decisions, particularly regarding the prioritisation of diversity in the cropping systems for agroecological purposes. The farming systems, in general, have therefore not undergone major changes in their cropping patterns, whilst there is a general heavy reliance upon input substitution for pest and soil fertility management. Fulfilment of agroecological ideals, based upon system redesign to create biodiversified cropping patterns and enhance pest management and nutrient cycling, is perhaps an end goal for organic farmers in a long transition. However, in the short term, a substantial conventionalisation is taking place at farms linked to the global value chain of certified organic produces.

The five case areas presented all operate in areas that have very few organic farms and therefore there is not much support from regional networks and institutions. The mechanisms that have brought about the conversion of such farms to organic are primarily economic. Under such conditions, farms become organic as they can produce a certain high-value commodity organically. Whether this is the infiltration of agribusiness into the organic sector, and thus conventionalisation, or basic market mechanisms can be discussed. However, at the farm scale, this process attracts farmers to convert to organic practices and perhaps this is why the presented farming practices do not fully live up to agroecological and organic principles. Farm management within such contexts where there is little institutional support for transition requires a degree of pragmatism in order to find a balance between agroecological and economic requirements. The reformulation of the IFOAM organic principles is an open attempt to accommodate the challenges of the globalisation of organic agriculture. Our analysis shows that whilst organic farmers abide to organic rules, there is a gap between what the standards require and the organic principles. Implementing farming practices which move toward the ideals of the principles thus becomes a decision of the farmer. The question is whether more principle-based rules are a feasible, or desirable, option for future regulation. 


\section{References}

Altieri M (1995) Agroecology: the science of sustainable agriculture, 2nd edn. Westview Press, USA

Altieri MA (1999) The ecological role of biodiversity in agroecosystems. Agr Ecosys Environ 74:19-31. doi:10.1016/S01678809(99)00028-6

Armsworth PR, Kendall BE, Davis FW (2004) An introduction to biodiversity concepts for environmental economists. Resour Energy Econ 26:115-136. doi:10.1016/j.reseneeco.2003.11.003

Bakewell-Stone P, Lieblein G, Francis C (2008) Potentials for organic agriculture to sustain livelihoods in Tanzania. Int J Agric Sust 6:22-36

Barberi P (2002) Weed management in organic agriculture: are we addressing the right issues? Weed Res 42:177-193

Bockstaller C, Girardin P, vander Werf HMG (1997) Use of agroecological indicators for the evaluation of farming systems. Eur J Agron 7:261-270

Buck D, Getz C, Guthman J (1997) From farm to table: The organic vegetable commodity chain of northern California. Soc Ruralis $37: 3-9$

Byrne J, Glover L, Alrøe HF (2006) Globalization and sustainable development: a political ecology strategy to realize ecological justice, In: Halberg N, Alrøe HF, Knudsen MT, Kristensen ES (eds) Global development of organic agriculture. CABI, pp. 49-74.

Darnhofer I, Lindenthal T, Bartel-Kratochvil R, Zollitsch W (2010) Conventionalisation of organic farming practices: from structural criteria towards an assessment based on organic principles. A review. Agron Sust Dev 30:67-81

FAO (2003) Compendium of agricultural-environmental indicators 1989-91 to 2000. Statistics Analysis Service, Statistics Division, Food and Agriculture Organization of the United Nations.

Fraser EDG (2006) Crop diversification and trade liberalization: Linking global trade and local management through a regional case study. Agric Human Val 23:271-281

Guthman J (2000) Raising organic: an agro-ecological assessment of grower practices in California. Agric Human Val V17:257-266. doi:10.1023/A:1007688216321

Guthman J (2004) The trouble with 'organic lite' in California: a rejoinder to the 'conventionalisation' debate. Soc Ruralis 44:301-315

Hall A, Mogyorody V (2001) Organic farmers in Ontario: an examination of the conventionalisation argument. Soc Ruralis 41:399-422

IFOAM (2005) The IFOAM basic standards for organic production and processing, IFOAM.

Kirchmann H, Kätterer T, Bergström L (2008) Nutrient supply in organic agriculture: plant availability, sources and recycling. In:
Kirchmann H, Bergström L (eds) Organic crop productionambitions and limitations. Springer, Netherlands, pp 89-116

Lampkin N (1990) Organic farming. Farming Press, UK

Lotter DW (2003) Organic agriculture. J Sustain Agric 21:59-128

Luttikholt LWM (2007) Principles of organic agriculture as formulated by the International Federation of Organic Agriculture Movements. NJAS - Wagen J Life Sc 54:347-360. doi:10.1016/S15735214(07)80008-X

Oelofse M, Høgh-Jensen H, Abreu L, Almeida G, El-Araby A, Hui Q, de Neergaard A (2010a) A comparative study of farm nutrient budgets and nutrient flows of certified organic and non-organic farms in China, Brazil and Egypt. Nutr Cycl Agroecosyst 87:455-470. doi:10.1007/s10705-010-9351-y

Oelofse M, Høgh-Jensen H, Abreu LS, Almeida GF, Hui QY, Sultan T, de Neergaard A (2010b) Certified organic agriculture in China and Brazil: market accessibility and outcomes following adoption. Ecol Econ 69(9):1785-1793

Parrott N, Marsden T (2002) The real green revolution: organic and agroecological farming in the south. Greenpeace Environmental Trust, United Kingdom

Raynolds LT (2004) The globalization of organic agro-food networks. World Dev 32:725-743

Rigby D, Bown S (2003) Organic food and global trade: is the market delivering agricultural sustainability? University of Manchester, School of Economic Studies

Rigby D, Caceres D (2001) Organic farming and the sustainability of agricultural systems. Agric Syst 68:21-40

Schmutz U, Rayns F, Firth C (2007) Balancing fertility management and economics in organic field vegetable rotations. J Sci Food Agr 87:2791-2793

Twarog S (2006) Organic agriculture: a trade and sustainable development opportunity for developing countries, UNCTAD Trade and Environment Review 2006. United Nations New York and Geneva, pp. 161-223.

Watson CA, Atkinson D, Gosling P, Jackson LR, Rayns FW (2002) Managing soil fertility in organic farming systems. Soil Use Manage 18:239-247

Willer H, Kilcher L (2010) Organic agriculture worldwide: current statistics, In: Willer H, Kilcher L (eds) The world of organic agriculture. Statistics and emerging trends 2010. FIBL-IFOAM Report. IFOAM, Bonn; FiBL, Frick; pp. 25-58.

Willer H, Rohwedder M, Wynen E (2009) Organic agriculture worldwide: current statistics, In: Willer H, Kilcher L (eds) The world of organic agriculture. Statistics and emerging trends 2009. FIBL-IFOAM Report. IFOAM, Bonn; FiBL, Frick; ITC, Geneva, pp. 25-58.

Zehnder G, Gurr GM, Kühne S, Wade MR, Wratten SD, Wyss E (2007) Arthropod pest management in organic crops. Annu Rev Entomol 52:57-80 